\title{
The Effects of Blanching, Harvest Time and Location (with a Minor Look at Postharvest Blighting) on Oleoresin Yields, Percent Curcuminoids and Levels of Antioxidant Activity of Turmeric (Curcuma longa) Rhizomes Grown in Jamaica
}

\author{
Cheryl E Green* and Sylvia A Mitchell
}

The Biotechnology Centre, Faculty of Science and Technology, University of the West Indies, Mona Campus, Kingston 7, Jamaica, West Indies

\begin{abstract}
Turmeric (Curcuma longa) grown in Jamaica was studied for its naturally occurring linear diarylheptanoid compounds namely curcumin, Bis-Demethoxy Curcumin (BDMC), Demethoxy Curucmin (DMC) and for its antioxidant activity. Evaluations were conducted on the basis of whether or not there were any potential effects of blanching, harvest time and location of growth on the quantity and quality of turmeric oleoresins. The highest antioxidant activity of $92.86 \%$ was obtained from turmeric rhizomes grown in the parish of Hanover while the highest turmeric oleoresin yields of $14.87 \%$ were obtained from the 15 minute blanched-treated turmeric rhizomes. With a new analog-selective RP-HPLC method, the curcumin, DMC, and BDMC were qualified and quantified. It was found that the highest yield of curcumin content of $22.69 \%$ was obtained from the 15 minute 'blanched' samples grown in the parish of Hanover from the $1^{\text {st }}$ harvest period of the study. An analytical method validation with linear equations and correlation of regressions of $R^{2}=0.9991, R^{2}=0.9993, R^{2}=0.9998$ and $R^{2}=0.9992$ for inter-day precision analyses were performed to validate the HPLC method.
\end{abstract}

Keywords: Curcuma longa; Turmeric grown in Jamaica; Antioxidant activity; Blanching; Post-harvest; Effect of harvest time; Curcumin; Curcuminoids; Bis-demethoxy curcumin (BDMC); Demethoxy curcumin (DMC); DPPH (2, 2-diphenyl-1-picrylhydrazyl); Turmeric oleoresin; Blighting; Geographic effects on plant compounds; Spices

\section{Introduction}

In the midst of several 'consumer trends', culinary spices find themselves at a juncture in the food industry as they transition from conventional spices to 'nouveau healthy condiments'. Along with the bold flavour, ethnic flair and functional attributes, spices are healthy and natural, giving consumers an 'all-in-one' package deal. Culinary herbs and spices are enjoying this renaissance for the medicinal properties that they provide, as modern science proves the health promoting benefits that come from eating them [1].

Much of the focus about herbs and spices is in relation to their antioxidant content and how that relates to cancer prevention and their anti-inflammatory properties $[2,3]$. In the human body, metabolic reactions produce free radicals with unpaired electrons which make them reactive so they can interact with important cellular components such as DNA and cell membranes leading to cell damage, disease and ageing. Antioxidants stabilize these unpaired electron species by oxidative or reductive reactions and thus deter the propagation of damaging chemical chain reactions to take place within the important cellular matrix [4]. According to recent studies, it was found that 'salad dressings' that contain herbs and spices increase the antioxidant capacity of the vegetable salad itself [1]. The American Institute for Cancer Research suggests that herbs and spices should be used for their health-protective phytochemicals to ward off cancer and other diseases [1].

The Jamaican spice industry is well-known and respected for its high quality [5]; it is also of paramount importance to the island's economy [6]. Turmeric has been identified as one of the top ten commonly produced spices in Jamaica [7]. However, growing and processing of the Jamaican turmeric is done on an 'ad hoc' basis by individuals in the principal turmeric-growing parishes throughout the island of Jamaica [8]. The Ministry of Agriculture and Fisheries (MOAF) a government ministry of Jamaica has recommended a system for the orderly conduct and development of the Jamaican spice industry which includes: production of planting material; quality control at the farmgate; dissemination of information to farmers about obtaining quality turmeric tubers; and the marketing, export and product promotion of the spice [9]. However, research to feed this improved system in Jamaica has been non-existent. This study was conceptualized out of the recognition that local Jamaican spice houses and Jamaican turmeric farmers will benefit from findings that will guide them to the best time to harvest and the best post-harvesting procedures to implement in order to acquire 'premium-grade' turmeric.

One step in the post-harvest processing of turmeric involves boiling or blanching the turmeric rhizomes [10]. Blanching (boiling in water for a set period of time) is carried out to facilitate the drying process of the rhizomes, to allow the starch granules to gelatinize and to inactivate enzymes $[11,12]$. The aim of this research was to evaluate a number of parameters that may impact the quality of turmeric during this postharvest step. The parameters evaluated included blanching time, the time of year of harvest and the location where the turmeric was grown. The results from this study will provide information on the optimum time to harvest turmeric and how to further improve the post-harvest processing of turmeric. This information is beneficial to buyers and sellers of turmeric as this spice is deemed as an economically important value added product with proven health and anti-aging benefits $[13,14]$.

*Corresponding author: Cheryl E Green, The Biotechnology Centre, Faculty of Science and Technology, University of the West Indies, Mona Campus, Kingston 7, Jamaica, West Indies, Tel: 876-977-1828; E-mail: greence100@yahoo.com

Received September 11, 2014; Accepted November 05, 2014; Published November 10, 2014

Citation: Green CE, Mitchell SA (2014) The Effects of Blanching, Harvest Time and Location (with a Minor Look at Postharvest Blighting) on Oleoresin Yields, Percent Curcuminoids and Levels of Antioxidant Activity of Turmeric (Curcuma longa) Rhizomes Grown in Jamaica. Mod Chem appl 2: 140. doi:10.4172/23296798.1000140

Copyright: $\odot 2014$ Green CE, et al. This is an open-access article distributed under the terms of the Creative Commons Attribution License, which permits unrestricted use, distribution, and reproduction in any medium, provided the original author and source are credited. 
Citation: Green CE, Mitchell SA (2014) The Effects of Blanching, Harvest Time and Location (with a Minor Look at Postharvest Blighting) on Oleoresin Yields, Percent Curcuminoids and Levels of Antioxidant Activity of Turmeric (Curcuma longa) Rhizomes Grown in Jamaica. Mod Chem appl 2: 140. doi:10.4172/2329-6798.1000140

Page 2 of 9

\section{Materials and Methods}

\section{Chemicals}

Commercial curcumin standard was purchased from Sigma Aldrich (St. Louis, MO). Turmeric standards kit containing curcumin, demethoxy curcumin and bis-demethoxy curcumin was purchased from Chroma Dex, Irvine, CA. The 1,1-diphenyl-2-picrylhdrazl (DPPH) was procured from Sigma Aldrich, St. Louis, MO. The 95\% ethanol was purchased from Pharmco-AAper (Shelbyville, KY). HPLC grade isopropanol, acetonitrile and methanol and Fisher brand $25 \mathrm{~mm}$ $0.45 \mu \mathrm{m}$ nylon syringe filters were purchased from Fisher Scientific (Fair Lawn, NJ). Whatman No. 1 filter paper was purchased from Whatman International Ltd. Maidstone, England.

\section{Plant material}

Turmeric was collected from two locations; the first location was from the traditional turmeric farming area in the western end of the island in the parish of Hanover (HAN) and the second from the eastern end of the island in the parish of St. Andrew (SA). There were a total of four harvesting periods: 1) February from both locations; 2) March from both locations; 3 ) the last week of April in Hanover and the first week of May in St. Andrew; and 4) June from both locations. Turmeric is a hardy, prolific crop that grows mostly wild in Jamaica all year round [9]. However when turmeric is cultivated in Jamaica, it is planted in September/October and harvested May/June of the following year, at full maturation in the $9^{\text {th }}$ month of growth (as communicated by spice house, Betapac Ltd., Jamaica). Turmeric is reaped when the aerial leaves become 'dried-up' indicating readiness of 'harvest' for this spice.

\section{Blanching}

The $\mathrm{h}$ arvested turmeric $\mathrm{rhizomes}$ w ere $\mathrm{w}$ ashed to remove d ebris and dirt. They were divided into three portions whereby the first portion was 'not blanched' and was assigned as the 'control' group. The other two portions were blanched by placing the turmeric rhizomes in pots of water so that all the rhizomes were submerged ensuring that no parts of the rhizomes were above the water level. The second portion of turmeric was boiled for 15 minutes and the third portion was boiled for 30 minutes.

After b lanching, the turmeric $r$ hizomes w ere sliced, steam $\mathrm{d}$ ried and milled in an industrial miller with a mesh size of $1 /$ sh $^{\text {th }}$ of an inch. Due to insufficiency of turmeric rhizomes in the first harvesting period, there was no 30 minute-blanching batch from Hanover. Subsequent to harvesting in the $3^{\text {rd }}$ harvesting period, certain batches became blighted as they appeared moistened with an off-odour during the post-harvest procedure. Due to the nature of the study as a 'time-related' study, it was not possible to remedy the unforeseen blighting once the study was under way. The blighted samples were kept, analysed and the data derived from them were used as a 'case study' so as to address the effects of 'deleterious issues' such as post-harvest blighting of turmeric rhizomes. Discussion and data for the blighted batches are assigned with an asterisk therein.

\section{Classification of the samples}

The turmeric samples were labelled according to location, harvesting period and blanch-treatment administered to the rhizomes. Hence the following codes: HAN1-0 represents samples from Hanover from the first harvest period with no blanching, HAN1-15 for those blanched for 15 minutes and HAN1-30 for 30 minutes. Similar codes were given for the samples from St. Andrew (SA1-0, SA1-15 and SA1-30). Then those for the second harvest are HAN2-0, HAN2-15 and so on.

\section{Extraction of turmeric oleoresins}

Each harvested batch of turmeric that was dried and milled was subjected to the following extraction procedure. A 50 gram portion of the dried milled turmeric was weighed and $700 \mathrm{~mL}$ of $95 \%$ ethanol was added to it. The mixture was allowed to macerate for 5 hours. After extraction, the remaining solution was filtered by gravity under suction. The residue was re-extracted with ethanol for 2 hours. The remaining solution was filtered by gravity under suction. Both filtrates were pooled and concentrated in vacuo using a rotary evaporator with a water-bath set at $50^{\circ} \mathrm{C}$. The amount of oleoresin obtained, was weighed and the yield was calculated as percentage weight by weight $(\% \mathrm{w} / \mathrm{w})$.

\section{HPLC analysis of turmeric oleoresin}

$0.5 \mathrm{mg} / \mathrm{mL}$ turmeric oleoresin solution was prepared in HPLC grade methanol. A concentration of $0.5 \mathrm{mg} / \mathrm{mL}$ of commercial curcumin powder was prepared in HPLC-grade methanol. A stock solution of Bis-Demethoxy Curcumin (BDMC) and Demethoxy Curcumin (DMC) was prepared in methanol to yield $0.5 \mathrm{mg} / \mathrm{mL}$ solution. All prepared solutions were filtered through a $0.45 \mu \mathrm{m}$ nylon syringe filter.

\section{The HPLC settings}

A relatively medium-polar quaternary mobile phase was prepared with isopropanol, acetonitrile, distilled water and acetic acid in a 3.0:1.5:5.0:0.5 $\mathrm{v} / \mathrm{v}$ ratio. There was an injection volume of $20 \mu \mathrm{L}$, at a flow rate of $0.5 \mathrm{~mL} /$ minute, a run-time of 20 minutes, a wavelength setting at $420 \mathrm{~nm}$, using an Agilent LiChrospher reversed phase RP C18 $250 \times 4 \mathrm{~mm}$ id column and an isocratic elution mode. Each sample preparation was injected in duplicates, separately onto the stationary phase column.

\section{Preparation of a 4-point standard curve}

A stock solution of $0.25 \mathrm{mg} / \mathrm{mL}$ curcumin standard was prepared

\begin{tabular}{|c|c|c|c|c|}
\hline Hanover & Harvest 1 & Harvest 2 & Harvest 3 & Harvest 4 \\
\hline HAN control & $9.02 \pm 0.10^{b}$ & $12.00 \pm 0.00^{b}$ & ${ }^{*} 11.07 \pm 0.07^{b}$ & $14.21 \pm 0.46^{b}$ \\
\hline HAN-15 & $7.22 \pm 1.01^{b}$ & $9.06^{a}$ & ${ }^{\star} 8.83^{a}$ & $14.87^{a}$ \\
\hline HAN-30 & ND & $10.58 \pm 0.12^{c}$ & $9.03 \pm 0.95^{c}$ & $12.22 \pm 0.29^{b}$ \\
\hline St. Andrew & Harvest 1 & Harvest 2 & Harvest 3 & Harvest 4 \\
\hline SA-control & $6.82^{a}$ & $9.62 \pm 0.07^{c}$ & $8.20 \pm 0.48^{c}$ & $14.59 \pm 0.44^{b}$ \\
\hline SA-15 & $4.65^{a}$ & $8.26^{a}$ & $7.43 \pm 0.07^{b}$ & $14.34 \pm 0.27^{b}$ \\
\hline SA-30 & $6.78^{a}$ & $10.29 \pm 0.12^{b}$ & ${ }^{\star} 5.89 \pm 0.02^{b}$ & $12.96 \pm 0.60^{b}$ \\
\hline
\end{tabular}

${ }^{a}$ Mean values represent a single sample

${ }^{b}$ Mean values represent duplicates

'Mean values represent three replicates

" denotes the 'blighted' samples

Table 1: Mean percentage (\%) turmeric oleoresin with standard error ( \pm ) 
Citation: Green CE, Mitchell SA (2014) The Effects of Blanching, Harvest Time and Location (with a Minor Look at Postharvest Blighting) on Oleoresin Yields, Percent Curcuminoids and Levels of Antioxidant Activity of Turmeric (Curcuma longa) Rhizomes Grown in Jamaica. Mod Chem appl 2: 140. doi:10.4172/2329-6798.1000140

Page 3 of 9

in methanol. From this stock solution, serial dilutions were prepared to yield $0.125,0.0625,0.0312$ and $0.0156 \mathrm{mg} / \mathrm{mL}$ concentrations. A 4-point standard curve was generated by injecting each of the prepared serial dilutions of commercial curcumin standard onto the column. The linearity of the standard curve was assessed as correlation coefficient squared $\left(R^{2}\right)$ where $R^{2}>0.995$ is considered to be linear, shown in Table 1.

\section{An in vitro DPPH free radical-scavenging assay}

The bioassay method described by Williams et al. was used as the antioxidant assay in this study [15]. A $50 \mu \mathrm{g} / \mathrm{mL}$ turmeric oleoresin solution was prepared in methanol. A blank was prepared by measuring $2.2 \mathrm{~mL}$ of methanol. A $0.02 \% \mathrm{DPPH}$ stock solution was prepared in methanol. Accurately $400 \mu \mathrm{L}$ of the $0.02 \%(w / v)$ 1, 1-diphenyl-1picrylhdrazl (DPPH) was removed and added to the $50 \mu \mathrm{g} / \mathrm{mL}$ oleoresin solution. This mixture was allowed to incubate for 20 minutes prior to determining the absorbance at $517 \mathrm{~nm}$ using a UV-vis spectrophotometer. From the $0.02 \%$ DPPH stock solution, $400 \mu \mathrm{L}$ was removed and added to the methanol blank and was also allowed to be incubated along with the samples (above-mentioned) for 20 minutes prior to antioxidant activity measurements. Determination was conducted in duplicates.

DPPH is a stable free radical with a signature purple colour [14]. The turmeric oleoresins containing phenolic curcuminoids with radical scavenging activity reduced the 1, 1-diphenyl-2-picrylhdrazl (DPPH in the radical form) to the 2,2-diphenyl-1-picrylhydrazine (the reduced DPPH form) which is colourless. The percentage antioxidant activity (\% age $\mathrm{AA}$ ) was determined by the following equation [15].

\section{\% Antioxidant activity calculation:}

$$
\% A A=\frac{A b s_{\text {control }}-A b s_{\text {sample }}}{A b s_{\text {control }}} \times 100
$$

\section{Statistical analysis}

There were three independent variables in the studies; 1) the harvest season, an attribute variable; 2) the location, an attribute variable and 3) the blanching treatments, which is an 'active variable'. Both 'attribute' variables and the 'active' variable were evaluated on the basis of any potential effect they may have on the curcuminoid content, the oleoresin yields and the levels of antioxidant activities from the turmeric oleoresin.

There were three dependent variables in the study: namely the 1) curcuminoid content, 2) oleoresin yields and 3) antioxidant activity. These three dependent variables were assessed for whether or not they were affected by the independent variables: the time of harvest, location and blanching treatments.

Analysis of variance (ANOVA) was used to compare the variables with a significant difference at a $p$-value $<0.05$. The ANOVA was confined to data with corresponding values. With the application of a scatter plot for data points, the HPLC calibration curves with linear trend-lines, $\mathrm{R}$-squared $\left(\mathrm{R}^{2}\right)$ values and line equations were generated.
Microsoft (MS) excel was used to generate all of the statistical analyses for this study. Standard error was calculated for oleoresin yields, \% antioxidant activity and for the \% curcuminoids and the results were expressed as the 'mean' $\% \pm$ S.E. (standard error).

\section{Results}

Due to the relationship between curcuminoids and antioxidant activity and in order to accomplish the aim of the study, which is to assess the effects of blanching, harvesting and location on the quality and quantity of turmeric oleoresins, it was imperative to do the following tests: a gravimetric analysis to determine percent oleoresin yields; a HPLC analysis to determine curcuminoid content; and a bioassay to determine percent antioxidant activity of the turmeric oleoresins. The results from these analyses are discussed therein.

\section{Oleoresin yields}

In the parish of Hanover, the non-blanched rhizomes produced an increasing oleoresin yield over the period of study from $9.02 \%$ in the first harvesting period, $12.0 \%$ in the second and the highest yield of $14.21 \%$ in the fourth harvesting period (Table 1). From the parish of St. Andrew, the oleoresin yields also increased from $4.65 \%$ to $14.59 \%$ from the first to fourth harvest, respectively. Of the four harvesting periods, the highest oleoresin yields were obtained from the $4^{\text {th }}$ harvesting period (highest was $14.87 \%$ from the parish of Hanover and turmeric rhizomes blanched for 15 minutes) (Table 1). ${ }^{\star}$ It must be noted that the blighted turmeric samples had unexpectedly the same levels of oleoresin yields as all the corresponding samples.

\section{Curcuminoid content}

Figure 1 represents the HPLC chromatogram for the turmeric oleoresin. Curcuminoid content was expressed as 'percent purity curcuminoid'. The order of retention times corresponding to each of the three curcuminoid derivatives was in accordance with the retention of the same derivatives observed from another HPLC method in the literature [16]. Curcumin was the main active of all three curcuminoids and its peak was the most abundant of the three derivatives, a finding that was in keeping with that reported in the literature [16]. It is notable that from all three curcuminoid derivatives, the highest quantity of curcumionoids occurred in the $1^{\text {st }}$ harvest period with a noticeable decline in the other 3 ensuing harvest times (Table $2 a, 2 b$ and $2 c$ ).

The largest percent curcumin content of $22.96 \pm 0.04 \%$ was obtained from HAN1-15 (the first harvesting period from Hanover blanched for 15 minutes). The demethoxy curcumin (DMC) content reflected the same trend with the highest DMC content $(17.63 \pm 0.14 \%)$ obtained from the first harvest, grown in Hanover (Table $2 \mathrm{~b}$ ), however unlike the curcumin derivative, the control group (HAN1-0) had the highest DMC content. For the third derivative, bis-demethoxy curcumin (BDMC), there was also a similar trend with the highest levels (13.09 $\pm 0.04 \%$ ) obtained from HAN1-15 (Table 2c). ${ }^{\star}$ It must be noted that

\section{\% CURCUMIN}

\begin{tabular}{|c|c|c|c|c|}
\hline HANOVER & HARVEST 1 & HARVEST 2 & HARVEST 3 & HARVEST 4 \\
\hline HAN CONTROL & $20.47 \pm 0.08$ & $12.30 \pm 0.00$ & *2.68 \pm 0.01 & $11.32 \pm 0.00$ \\
\hline HAN-15 & $22.96 \pm 0.04$ & $11.36 \pm 0.11$ & *7.30 0.09 & $13.30 \pm 0.02$ \\
\hline HAN-30 & N.D. & $15.81 \pm 0.16$ & $12.14 \pm 0.06$ & $10.62 \pm 0.00$ \\
\hline ST. ANDREW & HARVEST 1 & HARVEST 2 & HARVEST 3 & HARVEST 4 \\
\hline SA-CONTROL & $13.19 \pm 0.00$ & $12.86 \pm 0.02$ & $9.44 \pm 0.12$ & $11.35 \pm 0.08$ \\
\hline SA-15 & $17.41 \pm 0.15$ & $16.56 \pm 0.01$ & $11.96 \pm 0.12$ & $9.47 \pm 0.08$ \\
\hline SA-30 & $13.74 \pm 0.05$ & $15.65 \pm 0.03$ & ${ }^{*} 5.09 \pm 0.01$ & $9.92 \pm 0.10$ \\
\hline
\end{tabular}

*Denotes the 'mean' values representing the 'blighted' samples from the $3^{\text {rd }}$ harvesting period.

Table 2a: Mean percentage (\%) curcumin content for four different harvested Curcuma longa rhizomes. 
Citation: Green CE, Mitchell SA (2014) The Effects of Blanching, Harvest Time and Location (with a Minor Look at Postharvest Blighting) on Oleoresin Yields, Percent Curcuminoids and Levels of Antioxidant Activity of Turmeric (Curcuma longa) Rhizomes Grown in Jamaica. Mod Chem appl 2: 140. doi:10.4172/2329-6798.1000140

Page 4 of 9

\begin{tabular}{|c|c|c|c|c|}
\hline \multicolumn{5}{|c|}{$\%$ DMC } \\
\hline HANOVER & HARVEST 1 & HARVEST 2 & HARVEST 3 & HARVEST 4 \\
\hline HAN-CONTROL & $17.63 \pm 0.14$ & $5.12 \pm 0.01$ & $* 4.39 \pm 0.01$ & $5.06 \pm 0.01$ \\
\hline HAN-15 & $17.52 \pm 0.07$ & $4.89 \pm 0.01$ & ${ }^{*} 4.78 \pm 0.04$ & $6.53 \pm 0.01$ \\
\hline HAN-30 & N.D. & $5.82 \pm 0.01$ & $7.02 \pm 0.05$ & $5.31 \pm 0.01$ \\
\hline ST. ANDREW & HARVEST 1 & HARVEST 2 & HARVEST 3 & HARVEST 4 \\
\hline SA-CONTROL & $11.60 \pm 0.02$ & $4.63 \pm 0.02$ & $6.25 \pm 0.08$ & $5.05 \pm 0.01$ \\
\hline SA-15 & $15.82 \pm 0.07$ & $5.27 \pm 0.00$ & $6.15 \pm 0.02$ & $4.61 \pm 0.06$ \\
\hline SA-30 & $11.75 \pm 0.04$ & $5.33 \pm 0.01$ & $* 3.25 \pm 0.01$ & $4.56 \pm 0.00$ \\
\hline
\end{tabular}

Table 2b: Mean percentage (\%) demethoxy curcumin (DMC) content for four different harvested Curcuma longa rhizomes.

\begin{tabular}{|c|c|c|c|c|}
\hline HANOVER & HARVEST1 & HARVEST 2 & HARVEST3 & HARVEST4 \\
\hline HAN-CONTROL & $12.41 \pm 0.10$ & $2.55 \pm 0.00$ & $* 1.71 \pm 0.01$ & $3.40 \pm 0.06$ \\
\hline HAN-15 & $13.09 \pm 0.04$ & $2.45 \pm 0.01$ & $* 2.99 \pm 0.03$ & $4.26 \pm 0.03$ \\
\hline HAN-30 & N.D. & $3.05 \pm 0.00$ & $4.88 \pm 0.02$ & $3.20 \pm 0.08$ \\
\hline ST. ANDREW & HARVEST1 & HARVEST 2 & HARVEST3 & HARVEST4 \\
\hline SA-CONTROL & $9.71 \pm 0.01$ & $2.40 \pm 0.00$ & $4.60 \pm 0.06$ & $3.20 \pm 0.12$ \\
\hline SA-15 & $11.15 \pm 0.04$ & $2.98 \pm 0.00$ & $5.88 \pm 0.01$ & $3.27 \pm 0.07$ \\
\hline SA-30 & $8.86 \pm 0.04$ & $3.05 \pm 0.01$ & $* 2.66 \pm 0.01$ & $3.12 \pm 0.03$ \\
\hline
\end{tabular}

Table 2c: Mean percentage (\%) Bis-demethoxy curcumin (BDMC) content for four different harvested Curcuma longa rhizomes.

\begin{tabular}{|c|c|c|c|c|}
\hline Hanover & Harvest 1 & Harvest 2 & Harvest 3 & Harvest 4 \\
\hline HAN control & $92.86 \pm 1.79$ & $90.53 \pm 0.42$ & $76.91 \pm 0.36$ & $90.60 \pm 0.17$ \\
\hline HAN-15 & $90.50 \pm 0.43$ & $90.27 \pm 0.91$ & $79.47 \pm 4.96$ & $92.58 \pm 0.04$ \\
\hline HAN-30 & ND & $92.55 \pm 0.34$ & $90.72 \pm 0.95^{c}$ & $91.31 \pm 0.34$ \\
\hline St. Andrew & Harvest 1 & Harvest 2 & Harvest 3 & Harvest 4 \\
\hline SA-control & $88.69 \pm 2.20$ & $92.11 \pm 0.13$ & $88.16 \pm 0.47$ & $91.78 \pm 0.13$ \\
\hline SA-15 & $92.77 \pm 0.16$ & $92.80 \pm 0.16$ & $89.38 \pm 1.10$ & $90.32 \pm 0.30$ \\
\hline SA-30 & $90.34 \pm 1.79$ & $92.11 \pm 1.32$ & ${ }^{*} 81.78 \pm 1.19$ & $91.68 \pm 0.27$ \\
\hline
\end{tabular}

'Denotes the 'mean' values representing the 'blighted' samples from the $3^{\text {rd }}$ harvest period.

Table 3: Mean percentage (\%) antioxidant activity with standard error ( \pm ).

the blighted samples had very low curcumin, BDMC and DMC content with levels as low as $2.68 \pm 0.01 \%$ for curcumin, suggesting the adverse effects of blighting on the 'quality' of the turmeric oleoresin (Table 2a).

\section{Antioxidant activity}

The amount of antioxidant activity was expressed as percent antioxidant activity per gram extract. This bioassay uses the DPPH as the 'model free radical' which is scavenged by compounds such as the curcuminoids inherent in turmeric (Curcuma longa) rhizomes. As a result of the scavenging of electrons, there was a decrease in the absorbance of the DPPH solution which was quantified at an absorbance reading of $517 \mathrm{~nm}$. The decrease in absorbance was inversely proportional to the antioxidant activity of the turmeric oleoresin (Table 3 ). The highest antioxidant activity of $92.86 \%$ came from Hanover, in the first harvesting period from the control samples, HAN1-0 (Table 3). All the samples tested were considered to be of 'high' antioxidant activity as compared to other plant materials in the literature [15]. * It must be noted that the blighted samples also had relatively 'high' antioxidant activity, for example there was $79.47 \%$ from the 15 minute blanched sample; however the blighted samples were consistently less than that of the untainted samples (Table 3). The turmeric oleoresins from this research were able to scavenge the free radicals (DPPH solution) at a concentration of $50 \mu \mathrm{g} / \mathrm{mL}$.

An overall look at the effects between the 'observed' and 'manipulated' variables via ANOVA

A One-Way Analysis of Variance (ANOVA) can test three or more "means" at a time by using variances [17]. ANOVA allows for the analysis of the interactive effects between variables and is ideal to test complex hypotheses [17]. The ANOVA was employed to give an 'overall effect' of the variables as it simultaneously compares the "means" in several groups as well as variances across groups [18](Table 4).

In this study the one-way analysis of variance (ANOVA) was used to evaluate the independent variables and their effects on the dependent, observed variables. The 'harvest period' had 4 levels (harvest 1, 2, 3, and 4); while 'location' had 2 levels (HAN [Hanover] and SA [St Andrew]) while the 'blanching treatments' had 3 levels $(0,15$ and 30 minutes treatment). ANOVA was confined to data with corresponding values.

Overall effects of 'blanching' on turmeric oleoresin yields, curcuminoid content and antioxidant activity via ANOVA

There were 9 sets of ANOVA analyses conducted in respect to the 'effects of blanching' on oleoresin yields, curcuminoid content and antioxidant activity of turmeric extract (Table 4). The first set of ANOVA involved the comparison between the control and the 15 minute blanching treatments for the harvest periods of 1,2 \& 4 in Hanover (HAN). No statistical significance was found in terms of oleoresin yields, curcuminoid content and antioxidant activity. When the control and 30 minute-blanching treatment was compared, there was a significant difference for oleoresin yield and antioxidant activity. For the comparison between the 15 and 30 minute blanching treatments, there was a significance in the percent curcumin content, with the higher levels of curcumin obtained from the 30 minute 
Citation: Green CE, Mitchell SA (2014) The Effects of Blanching, Harvest Time and Location (with a Minor Look at Postharvest Blighting) on Oleoresin Yields, Percent Curcuminoids and Levels of Antioxidant Activity of Turmeric (Curcuma longa) Rhizomes Grown in Jamaica. Mod Chem appl 2: 140. doi:10.4172/2329-6798.1000140

Page 5 of 9

\begin{tabular}{|c|c|c|c|c|c|c|}
\hline \multicolumn{7}{|c|}{ BLANCHING } \\
\hline Variables compared & Factors incorporated & $\%$ Oleoresins & \%Antioxidant & $\%$ Curcumin & $\%$ BDMC & $\%$ DMC \\
\hline Control vs. $15 \mathrm{~min}$ & Hanover, Harvest 1, $2 \& 4$ & NS & NS & NS & NS & NS \\
\hline Control vs. $15 \mathrm{~min}$ & St Andrew, Harvest 1, $2 \& 4$ & NS & NS & NS & NS & NS \\
\hline Control vs. $15 \mathrm{~min}$ & HAN \& SA, Harvest 1, $2 \& 4$ & NS & NS & NS & NS & NS \\
\hline Control vs. $30 \mathrm{~min}$ & Hanover, Harvest $2 \& 4$ & Control $>30 \mathrm{~min}$ & 30 min >control & NS & NS & NS \\
\hline Control vs. $\mathbf{3 0} \mathrm{min}$ & St Andrew, Harvest $2 \& 4$ & NS & NS & NS & NS & NS \\
\hline Control vs. $30 \mathrm{~min}$ & HAN \& SA, Harvest $2 \& 4$ & NS & NS & NS & NS & NS \\
\hline $15 \mathrm{~min}$ vs. $30 \mathrm{~min}$ & Hanover, Harvest $2 \& 4$ & NS & NS & $30 \min >15 \min$ & NS & NS \\
\hline $15 \mathrm{~min}$ vs. $30 \mathrm{~min}$ & St Andrew, Harvest $2 \& 4$ & NS & NS & NS & NS & NS \\
\hline $15 \mathrm{~min}$ vs. $30 \mathrm{~min}$ & HAN \& SA, Harvest $2 \& 4$ & NS & NS & NS & NS & NS \\
\hline \multicolumn{7}{|c|}{ HARVESTING } \\
\hline 2nd vs. 4th harvest & Hanover - 0, $15 \& 30$ & 4 th $>2 \mathrm{nd}$ & NS & NS & 4 th $>2 n d$ & NS \\
\hline 2nd vs. 4th harvest & St Andrew $-0,15 \& 30$ & 4 th $>2$ nd & NS & 2nd $>4$ th & 4 th $>2$ nd & NS \\
\hline 2nd vs. 4th harvest & HAN \& SA - 0, $15 \& 30$ & 4th $>2$ nd & NS & 2 nd $>4$ th & 4 th $>2 n d$ & NS \\
\hline 1st vs. 2nd harvest & HAN \& SA - $0 \& 15 \mathrm{~min}$ & $2 n d>1 s t$ & NS & $1 s t>2 n d$ & $1 s t^{t}>2 n d$ & $1 \mathrm{st}>2 \mathrm{nd}$ \\
\hline 1st vs. 4th harvest & HAN \& SA - 0 \& $15 \mathrm{~min}$ & 4 th $>1 \mathrm{st}$ & NS & 1st>4th & 1st>4th & 1st>4th \\
\hline 2nd vs. 4th harvest & HAN \& SA - $0 \& 15 \mathrm{~min}$ & 4 th $>2 n d$ & NS & NS & 4 th $>2$ nd & NS \\
\hline 1st vs. 2nd harvest & HAN - $0 \& 15 \mathrm{~min}$ & NS & NS & $1 \mathrm{st}>2 \mathrm{nd}$ & $1 \mathrm{st}>2 \mathrm{nd}$ & $1 \mathrm{st}>2 \mathrm{nd}$ \\
\hline 1st vs. 4th harvest & HAN - $0 \& 15 \mathrm{~min}$ & 4 th $>1 \mathrm{st}$ & NS & 1st $>4$ th & 1st $>4$ th & 1st>4th \\
\hline 2nd vs. 4th harvest & HAN - $0 \& 15 \mathrm{~min}$ & 4 th $>2 n d$ & NS & NS & 4 th $>2 n d$ & NS \\
\hline 1st vs. 2nd harvest & $\mathrm{SA}-0 \& 15 \mathrm{~min}$ & $2 n d>1 s t$ & NS & NS & 1st>2nd & 1st>2nd \\
\hline 1st vs. 4th harvest & $\mathrm{SA}-0 \& 15 \mathrm{~min}$ & 4 th $>1 \mathrm{st}$ & NS & 1st $>4$ th & 1st $>4$ th & 1st>4th \\
\hline 2nd vs. 4th harvest & $\mathrm{SA}-0 \& 15 \mathrm{~min}$ & 4 th $>2$ nd & 2nd $>4$ th & $2 n d^{>} 4$ th & 4 th $>2$ nd & NS \\
\hline \multicolumn{7}{|c|}{ LOCATION } \\
\hline HAN vs. SA & 1st, 2nd \& 4th harvest - $0 \& 15 \mathrm{~min}$ & NS & NS & NS & NS & NS \\
\hline HAN vs. SA & 2nd \& 4th harvest $-0,15 \& 30 \mathrm{~min}$ & NS & NS & NS & NS & $\mathrm{HAN}>\mathrm{SA}$ \\
\hline HAN vs. SA & 2nd harvest $-0,15 \& 30 \mathrm{~min}$ & $\mathrm{HAN}>\mathrm{SA}$ & NS & NS & NS & NS \\
\hline HAN vs. SA & 4th harvest $-0,15 \& 30 \mathrm{~min}$ & NS & NS & $\mathrm{HAN}>\mathrm{SA}$ & NS & $\mathrm{HAN}>\mathrm{SA}$ \\
\hline HAN vs. SA & Control - 1st , 2nd, \& 4th harvest & NS & NS & NS & NS & NS \\
\hline HAN vs. SA & $15 \mathrm{~min}$ - 1st , 2nd, \& 4th harvest & NS & NS & NS & NS & NS \\
\hline HAN vs. SA & $30 \mathrm{~min}-1 \mathrm{st}, 2 \mathrm{nd}, \& 4$ th harvest & NS & NS & NS & NS & NS \\
\hline
\end{tabular}

Table 4: ANOVA with p-value<0.05.

blanching treatment (Table 4).

Overall effect of 'harvesting time' on turmeric oleoresin yields, curcuminoid contents and antioxidant activities via ANOVA

Twelve sets of statistical ANOVA were conducted to assess the effects of harvesting periods on $\%$ oleoresin yields, $\%$ antioxidant activity levels, $\%$ curcumin, \% BDMC and \% DMC content (Table 4). The ANOVA analysis between the $2^{\text {nd }}$ versus $4^{\text {th }}$ harvest periods (incorporating all three blanching treatments) had a significant difference in 'oleoresin yields' and 'BDMC content' with the larger values occurring in the $4^{\text {th }}$ harvesting period. In the case of the 'curcumin content' the $2^{\text {nd }}$ harvest gave significantly higher yields. There was a significant difference between the harvesting periods except for antioxidant activity which only had one significant case of more antioxidant activity from the $2^{\text {nd }}$ harvest (Table 4).

Overall effect of 'location' on turmeric oleoresin yield, curcuminoid content and antioxidant activity via ANOVA

There were four cases of significant differences as it relates to effect of location on oleoresin, curcuminoid and antioxidant activity. This confirmed that there was a significantly higher oleoresin yields, $\%$ curcumin and \%DMC content from the parish of Hanover than from the parish of St Andrew (Table 4).

\section{Discussion}

Findings for the effects of blanching, harvesting and location on the \% oleoresin yields

The maximum oleoresin yield for the turmeric grown in Jamaica was $14.87 \%$; this is comparably high as it relates to the yields of " 6 to $10 \%$ " from a similar solvent extraction procedure of turmeric powder recorded in the literature [19]. Another literature review records oleoresin yields varying from as low as $4 \%$ to as high as $24.3 \%$ depending on the cultivar of turmeric tested [20].

To account for the effects of 'blanching length of time' on oleoresin yields, a similar study which evaluated the effects of blanching on the yields of turmeric oleoresins was identified for comparison purposes. The results from their studies showed that at 15,20, 25 and 30 minutes there was $4.99,4.98,4.86$ and $4.81 \%$ oleoresin yields respectively. Their yields were low and there was no apparent difference between them [21]. It is notable that the present study on turmeric grown in Jamaica had variations in oleoresin yields between blanching treatments (Table 1) and some of these differences were significant (Table 4). 
Citation: Green CE, Mitchell SA (2014) The Effects of Blanching, Harvest Time and Location (with a Minor Look at Postharvest Blighting) on Oleoresin Yields, Percent Curcuminoids and Levels of Antioxidant Activity of Turmeric (Curcuma longa) Rhizomes Grown in Jamaica. Mod Chem appl 2: 140. doi:10.4172/2329-6798.1000140

Page 6 of 9

There was progressive increase in the oleoresin yields with respect to the 'time' of harvest. This was evident in both locations, and this effect was significant (Table 4). An example of the increase was noticed in St Andrew where oleoresin yields of $4.65 \%$ from the $1^{\text {st }}$ harvest climbed to $14.34 \%$ in the $4^{\text {th }}$ harvest period, of the same 15 minute blanched treatment (Table 2).

Turmeric oleoresins contain endogenous pigments and essential oils [22]. According to Shiyou et al. [23], the essential oils of turmeric reach their maximum quantity at about 7.5 and 8 months of plant maturity and this could account for the increase in the oleoresin yields (over time) as turmeric oleoresins are comprised of essential oils [23]. As such, it is postulated that the increase in the turmeric oleoresin yields is in relationship to the maturity of the turmeric plant.

The effect of location takes into account microclimatic differences in rainfall and temperature from one location to the other. Climatic changes have an effect on the production of plant chemicals even of the same plant variety and there can be varying amounts of phytochemicals when the plant is grown in different soils under different weather conditions [24]. The result from this research showed that there were significantly higher oleoresin yields obtained from the parish of Hanover for the first three harvesting periods of the study but the percent yields were similar in the $4^{\text {th }}$ harvest period for both locations (Tables 1 and 4).

\section{Findings for the effects of blanching, harvesting and location on the curcuminoids content}

The $1^{\text {st }}$ harvest period for this research took place in the month of February considered the $5^{\text {th }}$ month of maturity for cultivated turmeric in Jamaica. There was a decrease of curcuminoid content between the $5^{\text {th }}$ and $9^{\text {th }}$ month of the growing season for turmeric in Hanover and it took place in the $6^{\text {th }}$ to $9^{\text {th }}$ month in St. Andrew, (Tables 2a-2c). This phenomenon of decrease of curcuminoid content with respect to plant maturity is in keeping with another study in literature by Shiyou et al.[23] whereby there was an increase in curcumin quantity with the highest yields occurring at $51 / 2$ month of maturity after which there was a noticeable decline of the pigments towards full maturity at the $9^{\text {th }}$ month, mimicking the very same trend found in this study with the turmeric grown in Jamaica [23].

It has been suggested that curcuminoids reach their peak during a certain stage of plant maturation as a consequence of dynamic changes such as plant growth, rate of biosynthesis and the probable decrease in gene expression for these pigments due to loss of plant vigor over time. As such, production of these metabolites decline and they remain in situ. Knowledge of the precursors and biosynthetic pathways responsible for the formation of these secondary metabolites in the growth cycle of turmeric is not fully understood [25].

In the literature with respect to the effects of blanching on curcumin content, a study was conducted to evaluate the length of boiling time on the curcumin content from turmeric. The results from their studies showed that boiling turmeric at 15,20, 25 and 30 minutes yielded curcumin contents of $4.23,4.21,3.91$ and $2.29 \%$ respectively [21]. It must also be noted that there was a 'difference' between the 15 and 30 minutes of boiling with almost $54 \%$ more curcumin content obtained from the 30 minutes of boiling in comparison to the 15 minute boiling treatment [21]. In the case of the turmeric grown in Jamaica, there was overall insignificant difference observed between the blanched samples (Table 4). However, there was one noticeable difference with the yields of curcuminoids from the parish of St. Andrew in the $1^{\text {st }}$ harvest period between the 15 minute and the 30 minute blanched treated samples whereby the 15 minute blanched treatment gave yields of $17.41 \%$ while the 30 minute blanched treatment gave yields of $13.74 \%$, (Table 2a); the same scenario was observed for the BDMC and the DMC (Table $2 b$ and 2c). Although small, this variation is consistent with the literature [21] and deserves attention and further study.

With respect to effect of location on curcuminoid content, the highest curcumin content from Hanover was $22.96 \%$ while the highest curcumin content from St Andrew was 17.41\% (Table 2a). The highest curcumin, the highest BDMC and the highest DMC contents all came from Hanover suggesting that this location was more favourable for yielding higher quantities of these metabolites from the turmeric rhizome (Tables 2a-2c).

\section{Findings for the effects of blanching, harvesting and location on the antioxidant activity of turmeric oleoresins}

The highest antioxidant activity of $92.8 \%$ came from the parish of St. Andrew, which was not significantly higher than that obtained from Hanover (Table 3, 4). It was however considerably higher than a comparable study in literature, conducted using a similar DPPH free radical methodology to determine the antioxidant activity of cultivated turmeric with results of $78.8 \%$ for organically grown turmeric and $67.5 \%$ for conventionally grown turmeric respectively [26]. These levels of antioxidant activity, though considerably high, were lower than those obtained from this research on turmeric grown in Jamaica, ${ }^{*}$ even the blighted ones (Table 3).

In the literature a similar blanching study was conducted on white saffron (Curcuma mangga) and the antioxidant activity obtained from the non-blanched white saffron in comparison to the 5 minutes blanched treated in $0.05 \%$ citric acid solution were different with a higher antioxidant activity obtained from the blanched treated samples [27]. The studies conducted on turmeric grown in Jamaica, showed minor differences; for example in the $1^{\text {st }}$ harvest period in St. Andrew the 15 minute blanched turmeric gave yields of $92.77 \%$ antioxidant activity while the 30 minute blanched treated turmeric gave yields of $90.34 \%$, but there was no significant differences (Table 4).

It is said that the levels of antioxidant activity of medicinal plants is dependent on harvesting or rather on the seasonal variations and the time of the year that the plant is reaped [28]. However, this was not in accordance with the results on turmeric grown in Jamaica whereby there was no apparent effect of harvesting on the level of antioxidant activity (Table 4 ).

With respect to the effects of location on the antioxidant activity of medicinal plants, from the literature it is said that geographical regions of growth have some impact on the antioxidant activity of medicinal plants [28]. However, in the case of the research done on the turmeric grown in Jamaica there was no apparent effect of location on the level of antioxidant activity from the turmeric oleoresins (Table 4).

\section{Inter-day Precision Analysis for HPLC validation}

A linear curve analysis was generated to confirm the accuracy of the HPLC method. This improved HPLC method achieves excellent

\begin{tabular}{|c|c|c|}
\hline Test day & Linear equation & Correlation of regression $\left.\mathbf{R}^{2}\right)$ \\
\hline Day 1 & $\mathrm{y}=702.03 \mathrm{x}-44.52$ & $\mathrm{R}^{2}=0.9991$ \\
\hline Day 2 & $\mathrm{y}=76617 \mathrm{x}-691.23$ & $\mathrm{R}^{2}=0.9993$ \\
\hline Day 3 & $\mathrm{y}=3076.2 \mathrm{x}+827.45$ & $\mathrm{R}^{2}=0.9998$ \\
\hline Day 4 & $\mathrm{y}=20391 \mathrm{x}+57.36$ & $\mathrm{R}^{2}=0.9992$ \\
\hline
\end{tabular}

Table 5: Calibration curves for the validation of the RP HPLC chromatograph method. 
Citation: Green CE, Mitchell SA (2014) The Effects of Blanching, Harvest Time and Location (with a Minor Look at Postharvest Blighting) on Oleoresin Yields, Percent Curcuminoids and Levels of Antioxidant Activity of Turmeric (Curcuma longa) Rhizomes Grown in Jamaica. Mod Chem appl 2: 140. doi:10.4172/2329-6798.1000140

Page 7 of 9

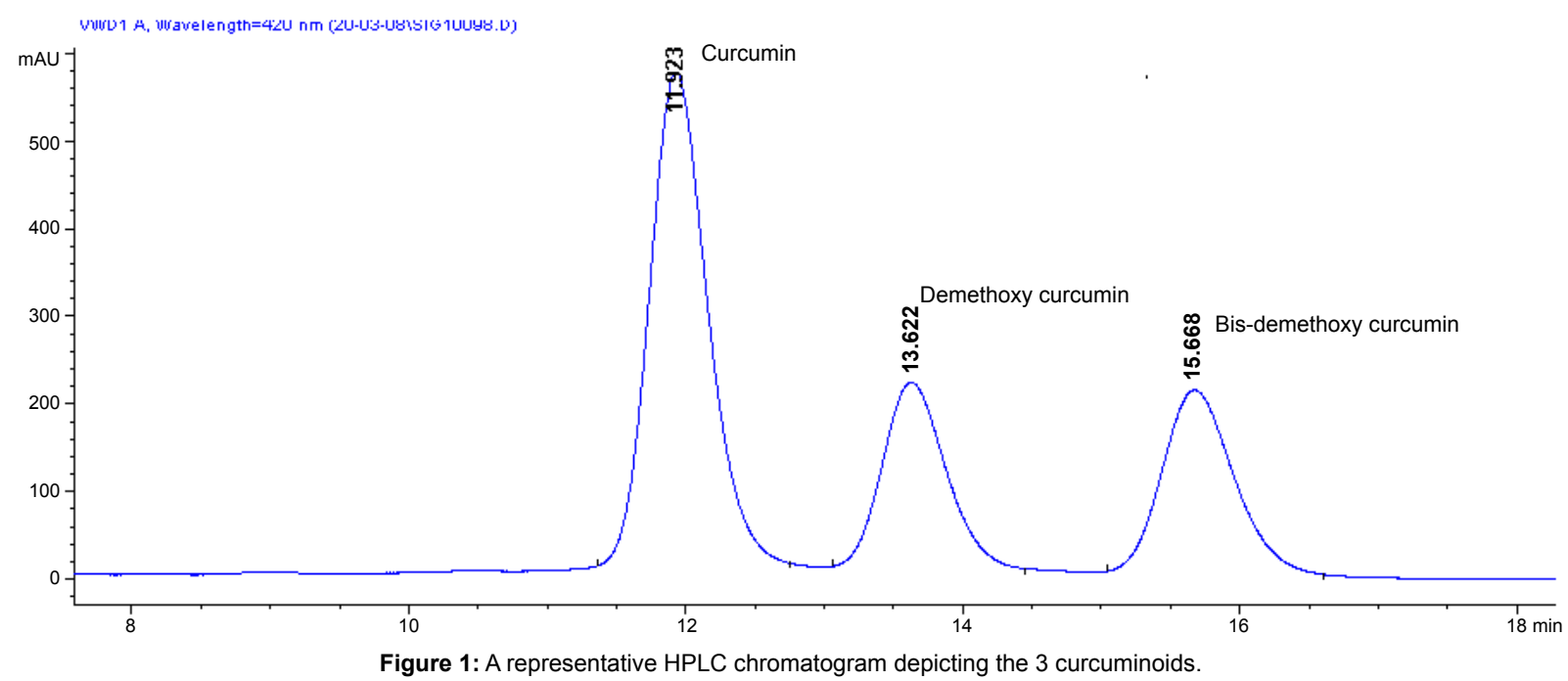

\section{Curcumin Standard Curve}

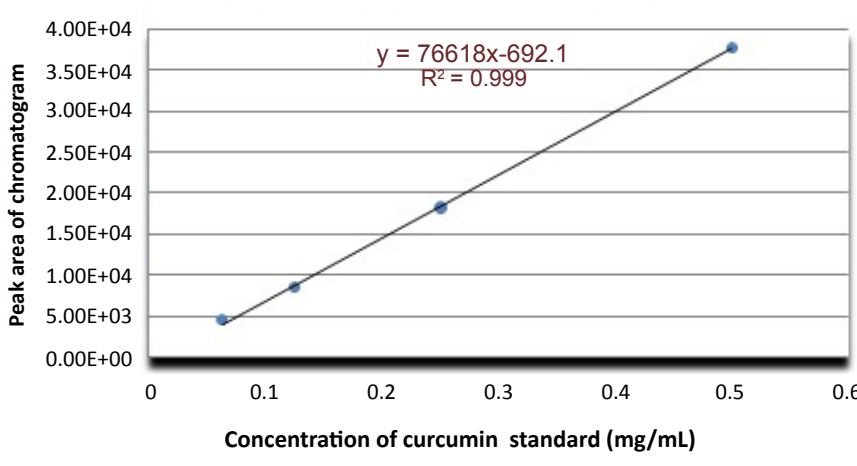

Figure 2: A representative standard curve plot for curcumin standard marker.

separation with a steady, noise-free baseline and with minimum shouldering between the chromatographic peaks. The method is considerably 'sensitive' as it requires relatively low microgram quantities of the turmeric oleoresin and is detected at a relatively short run-time with all 3 compounds fully eluted at about 17 minutes with all three curcuminoid derivatives completely eluted (Figure 1). In comparison to another HPLC method in the literature, the sensitivity and run-time parameters are markedly improved with this method [16]. With the use of the newly developed reversed phase HPLC method, the curcumin, demethoxy-curcumin and the bis-demethoxy curcumin were qualitatively and quantitatively determined. The analytical method was validated with the application of inter-day precision with correlations of $\mathrm{R}^{2}=0.9991, \mathrm{R}^{2}=0.9993, \mathrm{R}^{2}=0.9998$ and $\mathrm{R}^{2}=0.9992$ for days $1,2,3$, and 4 respectively. Along with the $\mathrm{R}^{2}$ values, there was recovery data. For day one, there was an $\mathrm{R}^{2}$ value of 0.9991 with a corresponding recovery data of $y=702.03 x-44.52$, see table 5 for the other consecutive days. All the correlation of regressions had high $\mathrm{R}^{2}$ values indicating statistical soundness of the HPLC method, (Table 5). A representative standard curve for curcumin is shown in Figure 2. The inter-day precision method confirms the accuracy of the new optimized HPLC method as an ideal tool in the time analysis of endogenous pigments from turmeric oleoresins.

\section{The matter of postharvest blighting}

${ }^{\star}$ There was an outstanding decrease in the curcuminoid content observed in the blighted turmeric samples in the $3^{\text {rd }}$ harvest period (Tables $2 \mathrm{a}, 2 \mathrm{~b}$ and $2 \mathrm{c}$ ) and this occurrence is supported by research findings which have found that plant diseases such as 'root rot' suppress plant growth and plant quality [35]. The antioxidant activity of the turmeric oleoresin was also affected, with lower yields observed in the blighted samples (Table 3). Blighting is a cause of concern for tuberous spice rhizomes such as turmeric and ginger (both are from the Zingiberaceae plant family). A study was conducted to identify fungi and bacteria associated with the "postharvest rot" of ginger rhizomes (Zingiberofficinale Roscoe) in the Serrana region of Espírito Santo, Brazil. It was difficult to establish appropriate guidelines for the postharvest management of these ginger rhizomes in Brazil, due to the lack of information about the etiological agents associated with the rot [35]. The lack of information pertaining to the post-harvest pathology for turmeric requires further studies to curtail this problem.

\section{Summary}

Spices are often eaten daily and are one of the most promising and readily available sources of antioxidants. The findings in this research show that specific harvesting periods during the year produced the highest levels of curcumin, a compound recognized for its applications in the prevention of many degenerative diseases.

To fully appreciate the importance of the antioxidant activity of turmeric as evidenced in this study, leading to its application in the prevention of many degenerative diseases, the following information is relevant. There are important metabolic redox reactions that harness electrons and protons. This cellular activity is vital because proton movement is the driving force that provides the majority of ready energy (ATP) for the cell as nutrients are broken down. Reduction involves the addition of negatively charged electrons and it is an endergonic reaction as it takes the compound to a higher energy state. Redox reactions are important in metabolism as they relate to energy carrier compounds, nicotinamide adenine dinucleotide $\left(\mathrm{NAD}^{+} / \mathrm{NADH}\right)$ and flavin adenine dinucleotide $\left(\mathrm{FAD} / \mathrm{FADH}_{2}\right)$. These two molecules are specialized hydrogen carriers as they transport hydrogens and their associated energy to specialized metabolic pathways that generate energy (ATP) via the use of $\mathrm{O}_{2}$ [40]. However during these metabolic reactions, reactive oxygen species or free radicals, such as superoxide anion are generated and these have detrimental effects on human health. Antioxidants can 
inhibit or retard oxidation either by scavenging the free radicals that initiate oxidation or by breaking the oxidative chain reactions [41]. Free radicals are implicated in cell aging, cell damage, damaged tissue, chronic diseases and overall poor health [15]. Research has indicated that there is a superfluous amount of active oxygen radicals produced in the human body causing stress at the cellular level and consequently inflammation, aging and diseases [29]. Biochemical processes such as reduction of oxygen (via enzyme oxidases), phagocytosis, and the formation of "advanced glyco-oxidation end products" (also known as AGEs) are constant sources that generate these free radicals. Environmental pollutants also add to the intracellular formation of Reactive Oxygen Species (otherwise known as ROS). Furthermore there are reactive nitrogen species such as nitric oxide $(\mathrm{NO})$ and peroxynitrate $\left(\mathrm{OONO}_{2}\right)$ which when combined overwhelms the body's antioxidant defense system leading to a biochemical state called 'oxidative stress' [15]. There is growing evidence that acute overproduction of Reactive Oxygen Species (ROS) under pathophysiologic conditions is implicated in cardiovascular diseases [15]. A number of drugs termed 'antioxidants' such as $\beta$-blockers, inhibitors such as angiotensin-converting enzyme and calcium antagonists to name just a few have been administered to manage heart diseases [15]. There are another class of antioxidants namely the 'spice antioxidants' and these are important in the chemoprevention of lipid peroxidation, inflammation, cancer and the overall retardation of the aging process [29]. Curcumin, a spice antioxidant, has been confirmed as a complementary natural alternate medicine for cancer treatment [30].

Increase in consumer and food manufacturer interests in 'natural alternates' has led to an astronomical increase of $175 \%$ 'natural alternatives' between 1989 and 1990. During that time, the number of products that made claims to be 'without additives or preservatives' rose by $99 \%$ [31]. As a consequence, much emphasis has been given to the identification of natural antioxidants in food products. The research on natural antioxidants has developed enormously and there has been an enhanced public awareness of health issues too. Natural antioxidants have some advantages that their synthetic counterparts do not have. In the first place, natural antioxidants are more readily acceptable over the synthetic antioxidants; this is due to the fact that natural antioxidants are considered safe and many of them are identified on the Generally Recognized as Safe (GRAS) list. Turmeric is classified as a 'CPG Sec. 525.750 spice' on the GRAS list [32]. The rigorous criteria and procedures used to evaluate the "safety" of all substances on the GRAS list did not warrant genotoxicity analysis of the turmeric oleoresins in this study. This procedure includes many scientific studies on the genotoxicity of turmeric which have conclusively shown the safety of turmeric, curcumin and essential oil derivatives. Indeed, turmeric has been found to alleviate genotoxicity induced by other agents [42]. Also, a test for genotoxicity was not needed for this paper as it delves into the factors that may affect production of the curcumin in the plant and not on its effect in humans.

In the case of synthetic antioxidants there are concerns regarding the pathological effects of using them and this has prompted studies to find natural alternatives in the last few decades [33]. Butylated hydroxyanisole (BHA) and buytlated hydroxytoluene (BHT) are two well-known synthetic antioxidants used as food additives however they are restricted in some countries due to the possibility that they may have undesirable effects on the enzymes of human organs. Due to this controversy, there is growing interest in finding safe substitutes from natural resources such as edible plants, herbs and spices [33].

It is a 'paradox' that on the one hand 'oxygen' is needed to sustain life but on the other hand oxygen is the primary cause for oxidative stress in the human body and the degradation of foods. In order to address this issue there has been much focus on the involvement of free radicals responsible for aging and diseases [15]. Antioxidants are the defence system in vivo and the first line of defence to inhibit the formation of Reactive Oxygen Species (ROS) and free radicals which are implicated in many degenerative diseases such as cancer [34].

\section{Conclusion}

This study is the first analysis done on Jamaican turmeric and it has exposed their high quality. The maximum levels of curcuminoids occurred in the month of February and March, in Hanover and St. Andrew respectively. Maximum turmeric oleoresins occurred in the month of June in both locations. The overall anti-oxidant activity levels were high throughout the four harvesting periods, and in both locations, and are comparatively high in comparison to similar studies in literature [15]. These results warrant further more in-depth study with more samples and more locations to further analyze the factors that lead to high quality turmeric harvest. The high anti-oxidant activity for the turmeric extract should also lend leverage for the locally grown turmeric in Jamaica as an important spice with value-added benefits for its medicinal and health enhancing applications.

\section{Recommendations}

Despite the fact that there was minor impact of blanching on curcuminoid content, oleoresin yields and antioxidant activities (Table 4), information from the literature considers blanching a good post harvesting practice and an important preparative step hence it is recommended [36].

Curcumin is a 'quality indicator' as it is used to measure the colour value of turmeric as well as its antioxidant properties [37,38]. If the buyer of turmeric is interested in the 'quality' of turmeric oleoresin which is indicative of the abundance of curcumin content, then it is suggested that the turmeric rhizome be harvested about the $5^{\text {th }}$ and $6^{\text {th }}$ month of maturity when the curcuminoids were found to be at their maximum peak. However if the buyer of turmeric is more interested in 'quantity' of turmeric oleoresin, then the turmeric rhizome should be reaped at full maturity in accordance to the research results from this study. The opportunity to harness the highest levels of curcumin from turmeric is important as it is a highly therapeutic secondary metabolite [39].

\section{Acknowledgment}

This study was funded by an Environmental Foundation of Jamaica (EFJ) grant and a UWI research and publication grant. The utilization of certain laboratory instruments was made possible through the Scientific Research Council, Kingston Jamaica, and the Chemistry Department of the University of the West Indies, Mona campus, Kingston Jamaica. We are grateful and thankful to everyone who enabled the successful completion of this study. The research study is in the partial fulfilment for the PhD thesis for Cheryl E Green

\section{References}

1. Palmer S (2008) Food Product Design-Herbs and Spices: Hot and Healthy. Food Product Design.

2. Milner JA, Romagnolo DF (2010) Bioactive Compounds and Cancer. Humana Press, Springer, New York, NY, USA, pp 671.

3. Ninfali P, Mea G, Giorgini S, Rocchi M, Bacchiocca M (2005) Antioxidant capacity of vegetables, spices and dressings relevant to nutrition. $\mathrm{Br} \mathrm{J}$ Nutr 93: $257-266$.

4. Whitney E, Rady R (2012) Understanding Nutrition.Cengage Learning, Belmont, CA, USA, pp 361

5. Jamaica Promotions Corporation (2012) Flavours of Jamaica, JAMPRO 
Citation: Green CE, Mitchell SA (2014) The Effects of Blanching, Harvest Time and Location (with a Minor Look at Postharvest Blighting) on Oleoresin Yields, Percent Curcuminoids and Levels of Antioxidant Activity of Turmeric (Curcuma longa) Rhizomes Grown in Jamaica. Mod Chem appl 2: 140. doi:10.4172/2329-6798.1000140

Page 9 of 9

publication, Kingston, Jamaica, p. 44.

6. Richardson MA (1993) A paper on spices and aromatic plants produced in Jamaica relative to roundtable on the development of spices and aromatics in the CARICOM countries 12th -15th October, 1993, Jamaica p. 1.

7. Export Centre and Business Information Point (2008) Market Brief-Sauces and Spices Bulletin. Jamaica Exporters Association, p. 5.

8. (1991) Report of the third meeting of the International Spice Group: Kingston, Jamaica, 18-23 November.

9. Collinder A (2012) 510 acres to be planted with ginger, turmeric. Business section, the Jamaica Gleaner.

10. Parthasarathy VA (2008) Organic Spices. New India Publishing Agency, New Delhi, India, pp 420.

11. Plotto A (2004) Turmeric: Post-Production Management, Food and Agriculture Organization of the United Nations (FAO), p 10.

12. Panda $H$ (2010) Handbook on Spices and Condiments (Cultivation, Processing and Extraction). Asia Pacific Business Press Inc., New Delhi, India, pp 22

13. Comstock F (2010) Antiaging 101: Course Manual: A Proactive Preventive Health Care Program. AuthorHouse, Bloomington, USA, pp 89

14. Jain PK, Agrawal RK (2008) Antioxidant and Free Radical Scavenging Properties of Developed Mono- and Polyherbal Formulations, Asian J Exp Sci 22: $213-220$

15. Williams LAD, Hibbert SL, Porter RBR,Bailey-Shaw YA, Green CE (2006) Jamaican plant with in vitro anti-oxidant activity. In Biologically active natural products for the 21st Century. Research Signpost, Kerala, India, Chapter 2. pp. $2,3,8,11$.

16. Green CE, Hibbert SL, Bailey-Shaw YA, Williams LA, Mitchell S, et al. (2008) Extraction, processing, and storage effects on curcuminoids and oleoresin yields from Curcuma longa L. grown in Jamaica. J Agric Food Chem 56: 3664 3670.

17. (2014) Introduction to ANOVA / MANOVA.

18. (2014) Statistical Advisor, How to Compare Means / Variances in Multiple Groups.

19. Weise EA (2002) Spice Crops, CABI Publishing, New York, USA, pp 350.

20. Peter KV (2007) Underutilized and Underexploited Horticultural Crops.Volume 4, New India Publishing, Delhi, India, pp 339.

21. Shinde GU, Kamble KJ, Harkari MG, More GR (2011) Process Optimization in Turmeric Heat Treatment by Design and Fabrication of Blancher.Proceedings of International Conference on Environmental and Agriculture Engineering, IACSIT Press, Singapore 15: 40.

22. Pruthi JS (1998) Quality Assurance in Spices and Spice Products, Modern Methods of Analysis.Alliend Publishers Limited, Mumbai, India, pp 505.

23. Li S, Yuan W, Deng G, Wang P, Yang P, et al. (2011) Chemical Composition and Product Quality Control of Turmeric (Curcuma longa L.). Pharmaceutical Crops 2: 28-54.

24. Bonakdar RA (2012) The H.E.R.B.A.L. Guide: Dietary Supplement Resources for the Clinician. Lippincott Williams \& Wilkins, Philadelphia, PA, USA, pp 169.
25. Fraga CG (2009) Plant Phenolics and Human Health: Biochemistry, Nutrition and Pharmacology. Volume 1 of The Wiley-IUBMB Series on Biochemistry and Molecular Biology, John Wiley \& Sons, Hoboken, NJ, USA, pp 31

26. Roghelia V, Patel VH (2013) Antioxidant profile of organically and conventionally grown fresh turmeric (Curcuma longa L): A comparative study. J Cell and Tissue Research 13: 3749-3751.

27. Pujimulyani D, Raharjo S, Marsono Y, Santoso U (2013) The Phenolic Substances and Antioxidant Activity of White Saffron (Curcuma mangga Val.) as Affected by Blanching Methods.Intl $\mathrm{J}$ of BioVetAgric and Food Engineering 7: 606-609.

28. Škrovánková S, Mišurcová L, Machů L (2012) Antioxidant activity and protecting health effects of common medicinal plants. Adv Food Nutr Res 67: 75-139.

29. Shahidi F (1997) Natural Antioxidants: Chemistry, Health Effects, and Applications. AOCS Press, Champaign, IL, USA, pp 73.

30. Alaoui-Jamali M (2010) Alternative and Complementary Therapies for Cancer: Integrative Approaches and Discovery of Conventional Drugs. Springer Science \& Business Media, New York, NY, USA, pp 63.

31. Madhavi DL, Deshpande SS, Salunkhe DK (1995) Food Antioxidants: Technological: Toxicological and Health Perspectives. CRC Press, Boca Raton, FL, USA, pp 73

32. US FDA (2014) Inspections, Compliance, Enforcement, and Criminal Investigations. U.S. Food and Drug Administration

33. Charles DJ (2012) Antioxidant Properties of Spices, Herbs and Other Sources. Springer Science \& Business Media, New York, USA, pages 55, 570.

34. Lobo V, Patil A, Phatak A, Chandra N (2010) Free radicals, antioxidants and functional foods: Impact on human health. Pharmacogn Rev 4: 118-126.

35. Moreira SI, Dutra DC, Rodrigues AC, de Oliveira JR, Dhingra OD, et al. (2013) Fungi and bacteria associated with post-harvest rot of ginger rhizomes in Espirito Santo, Brazil. Trop plant pathol 38: 218.

36. Elliott SM (2003) Rhizome rot disease of ginger. Crop and Plant Protection Unit, Ministry of Agriculture, Bodles Research Station, Jamaica.

37. Sforza S (2013) Food Authentication using Bioorganic Molecules. DEStech Publications, Inc. Lancaster, PA, USA, pp 299.

38. Dasgupta A, Hammett-Stabler C (2011) Herbal Supplements: Efficacy, Toxicity Interactions with Western Drugs, and Effects on Clinical Laboratory Tests. John Wiley \& Sons, Hoboken, NJ, USA, pp 198.

39. Hickey S, Saul AW (2010) The Vitamin Cure for Migraines. Basic Health Publications Inc., Laguna Beach, CA, USA, pp 147.

40. Brown SP, Miller WC, Eason JM (2006) Exercise Physiology: Basis of Human Movement in Health and Disease. Lippincott Williams \& Wilkins Publishers, Baltimore, MD, USA, pp 55.

41. Venugopal V (2011) Marine Polysaccharides: Food Applications. CRC Press, Boca Raton, FL, USA, pp 167.

42. Nirmala K, Panpatil VV, Raja Kumar AK, Balakrishna N, Balansky R (2011) Turmeric alleviates benzo(a)pyrene induced genotoxicity in rats: Micronucle formation in bone marrow cells and DNA damage in tissues. International Journal of Cancer Research 7: 114-124. 